\title{
Delinquent Behavior and Emerging Substance Use in the MTA at 36 Months: Prevalence, Course, and Treatment Effects
}

\author{
BROOKE S.G. MOLINA, Ph.D., KATE FLORY, Ph.D., STEPHEN P. HINSHAW, Ph.D., \\ ANDREW R. GREINER, B.S., L. EUGENE ARNOLD, M.D., JAMES M. SWANSON, Ph.D., \\ LILY HECHTMAN, M.D., PETER S. JENSEN, M.D., BENEDETTO VITIELLO, M.D., \\ BeTSY HOZA, Ph.D., WILliam E. PELHAM, Pн.D., GLEN R. ElliOTT, Ph.D., M.D., \\ KAREN C. WELlS, Ph.D., HOWARD B. ABIKOFF, Ph.D., ROBERT D. GIBbONS, Ph.D., \\ SUE MARCUS, Ph.D., C. KEITH CONNERS, Ph.D., JEFFERY N. EPSTEIN, Ph.D., \\ LAURENCE L. GREENHILL, M.D., JOHN S. MARCH, M.D., M.P.H., \\ JEFFREY H. NEWCORN, M.D., JOANNE B. SEVERE, M.S., AND TIMOTHY WIGAL, Ph.D.
}

\begin{abstract}
Objective: To compare delinquent behavior and early substance use between the children in the Multimodal Treatment Study of Children With ADHD (MTA; $N=487$ ) and those in a local normative comparison group $(n=272)$ at 24 and 36 months postrandomization and to test whether these outcomes were predicted by the randomly assigned treatments and subsequent self-selected prescribed medications. Method: Most MTA children were 11 to 13 years old by 36 months. Delinquency seriousness was coded ordinally from multiple measures/reporters; child-reported substance use was binary. Results: Relative to local normative comparison group, MTA children had significantly higher rates of delinquency (e.g., $27.1 \%$ vs. $7.4 \%$ at 36 months; $p=.000$ ) and substance use (e.g., $17.4 \%$ vs. $7.8 \%$ at 36 months; $p=.001$ ). Children randomized to intensive behavior therapy reported less 24-month substance use than other MTA children $(p=.02)$. Random effects ordinal growth models revealed no other effects of initial treatment assignment on delinquency seriousness or substance use. By 24 and 36 months, more days of prescribed medication were associated with more serious delinquency but not substance use. Conclusions: Cause-and-effect relationships between medication treatment and delinquency are unclear; the absence of associations between medication treatment and substance use needs to be re-evaluated at older ages. Findings underscore the need for continuous monitoring of these outcomes as children with attentiondeficithyperactivity disorder enter adolescence. J. Am. Acad. Child Adolesc. Psychiatry, 2007;46(8):1027-1039. Key Words: attention-deficit/hyperactivity disorder, treatment, multimodal, medication, substance use, delinquency.
\end{abstract}

Accepted January 4, 2007.

Please see end of text for author affiliations.

The work reported was supported by cooperative agreement grants and contracts from the National Institute of Mental Health to the following: University of California, Berkeley: U01 MH50461 and N01MH12009; Duke University: U01 MH50477 and N01MH12012; University of California, Irvine: UO1 MH50440 and NO1MH 12011; Research Foundation for Mental Hygiene (New York State Psychiatric Institute/Columbia University): U01 MH50467 and N01 MH12007; Long Island-Jewish Medical Center U01 MH50453; New York University: N01MH 12004; University of Pittsburgh: U01 MH50467 and NO1 MH 12010; and McGill University N01MH12008.- The Office of Special Education Programs of the U.S. Department of Education, the Office of Juvenile Justice and Delinquency Prevention of the Justice Department, and the National Institute on Drug Abuse also participated in funding.
Appreciation is extended to Dr. Patrick Curran, University of North Carolina, Chapel Hill, and Dr. Linda Muthén, Muthén \& Muthén, Los Angeles, for their guidance regarding the technical aspects of the growth modeling used in this article, and to Drs. Magda Stouthamer-Loeber, Rolf Loeber, and Steven Lee for their assistance regarding the delinquency coding strategies used herein.

The opinions and assertions contained in this report are the private views of the authors and are not to be construed as official or as reflecting the views of the National Institute of Mental Health, the National Institutes of Health, or the Department of Health and Human Services.

Correspondence to Dr. Brooke Molina, Department of Psychiatry, University of Pittsburgh School of Medicine, 3811 O' Hara Street, Pittsburgh, PA 15213; e-mail:molinab@upmc.edu.

0890-8567/07/4608-1027@2007 by the American Academy of Child and Adolescent Psychiatry.

DOI: $10.1097 /$ chi.0b013e3180686d96 
Childhood attention-deficit/hyperactivity disorder (ADHD) is associated with the later development of serious conduct problems (Hinshaw et al., 1993; Loeber et al., 1995) and substance use/substance use disorder (Gittelman et al., 1985; Molina and Pelham, 2003). Not all children with ADHD develop these problems, and the specificity of early ADHD as a risk factor is uncertain, given that co-occurring externalizing behavior problems often emerge as independent predictors (Lahey et al., 2000; Lee and Hinshaw, 2004; Lilienfeld and Waldman, 1990), but children with ADHD are nonetheless at risk. The children in the Multimodal Treatment Study of Children With ADHD (MTA) were 7.0 to 9.9 years old at study entry, causing them to be well below the age of maximum risk of these outcomes at the end of treatment 14 months later. By the 36-month assessment, however, $90 \%$ of the MTA children were between 11 and 13 years of age, on the threshold of adolescence when antisocial behaviors escalate (Loeber et al., 1991) and initiation of "gateway" drug use occurs (Kandel and Yamaguchi, 2002). Thus, our aims were to determine the extent of these developmentally and clinically salient behaviors at the 36-month assessment, their co-occurrence, and their course as a function of randomly assigned treatment and subsequent selfselected, prescription medication treatment.

A number of reports have described the results of the MTA at the 14- and 24-month assessments (Owens et al., 2003; Swanson et al., 2001; The MTA Cooperative Group, 1999a,b, 2004a,b). The companion article in this issue by Jensen et al. extends findings for primary outcome measures to the 36-month assessment. Across these reports, externalizing behaviors beyond ADHD symptoms were examined as symptoms of oppositional defiant disorder (ODD; The MTA Cooperative Group, 1999a, 2004a,b), ODD and ADHD symptoms aggregated (Swanson et al., 2001), a single measure composite indexing a range of impairments and symptoms beyond those of ADHD and ODD (Conners et al., 2001), or a composite of ODD and conduct disorder (CD) diagnoses (Arnold et al., 2005; Jensen et al., 2001). Such amalgamation was practical given the relatively low base rates of CD at baseline (14.3\%) and immediate posttreatment (6.5\%). However, given the age of the sample and the importance of examining conduct disordered and delinquent behaviors as outcomes in their own right, it is now time to appraise effects on delinquency-related behaviors per se.

A method for classification of delinquency seriousness was introduced by Wolfgang et al. (1985) and subsequently adapted for use with the boys in the Pittsburgh Youth Study (Loeber et al., 1991), a longitudinal study of urban boys in Pittsburgh. This clinically intuitive scoring algorithm classifies each child's delinquent behavior along a continuum of severity from mild (e.g., stealing an item worth less than $\$ 5$ ) to serious (e.g., attacking to seriously hurt or kill). This method, which makes use of information across measures and reporters, also allows "dynamic classification" of offenders such that differences across measurement occasions may be modeled to capture worsening, improving, or static clinical profiles. Thus, in longitudinal studies such as the MTA that feature multiple-method, multiple-reporter data sets, this strategy for studying delinquency provides a parsimonious and clinically relevant measure with demonstrated predictive utility and concurrent validity (Loeber et al., 1991). One study of adolescent boys with and without childhood ADHD used this method and found, in addition to significantly higher delinquency severity scores for the probands, increased risk of delinquency severity among boys with childhood histories of covert (e.g., stealing, property destruction) antisocial behavior (Lee and Hinshaw, 2004). In addition to illustrating the method's potential utility, this finding highlights the importance of measuring behaviors of which adult reporters may be relatively unaware.

A related concern for children with ADHD is their potential for substance use, abuse, and dependence, especially as influenced by their treatment with stimulant medications (see Wilens et al., 2003 for a review). An often-cited study (Biederman et al., 1999) reported that medication for ADHD is associated with decreased risk of substance use disorder, but replication is crucial for a number of reasons, including the small size (56 medicated vs. 19 unmedicated adolescents) and large group differences at baseline in variables that contribute to substance use (age, lifetime risk of CD, previous substance use disorder). At 36 months the MTA children were still below the age of high risk of substance abuse or dependence, but initial use of alcohol, tobacco, and occasionally illicit drugs can begin at this age. Although adolescent experimentation with substances legal for adult use may be normative, 
substance use at an atypically young age is associated with later substance-related problems (e.g., Grant and Dawson, 1997). Thus, in addition to comparing early substance use between the MTA and our local normative comparison group (LNCG), an important clinical question is whether treatment history, either randomly assigned or self-selected, is associated with emerging substance use in early adolescence.

Using data from the MTA through 36 months (including the 24-month assessment), we compared the extent of serious delinquent behavior and emerging substance use (not abuse or dependence) for the children in the MTA compared to our LNCG, which was recruited at the 24-month assessment. We also examined whether our initial, randomly assigned treatments and subsequent self-selected prescription medication use were associated with an increase or decrease in delinquency over time, with participants' levels of delinquency, and with substance use at the 24- and 36-month assessments.

\section{METHOD}

\section{Participants}

Participants were 579 MTA children with DSM-IV ADHD Combined type and an additional 289 LNCG children (described below). Each of 6 sites randomized 96 to 98 children to one of four treatment groups: intensive multicomponent behavior therapy (Beh), intensive medication management (MedMgt), the combination of Beh and MedMgt (Comb), or referral to usual community care (CC). At baseline (pretreatment), participants were 7.0-9.9 years of age (mean 8.5 years, SD 0.8). The MTA recruitment strategy, procedures for diagnosing ADHD, treatment specifics, and sample demographics have been described elsewhere (Arnold et al., 1997; Greenhill et al., 1996, 2001; Hinshaw et al., 1997; The MTA Cooperative Group, 1999a,b, 2004a,b; Wells et al., 2000).

Participants were reassessed at completion of the 14-month treatment phase (mean age [SD] 9.57 [0.84] years; range 8-12 years), at 24 months postrandomization (mean age [SD] 10.43 [0.86] years; range 9-12 years), and at 36 months postrandomization (mean age $[\mathrm{SD}] 11.72$ [0.92] years; range 10-14 years). Participant retention rate was $97 \%$ at 14 months, $93 \%$ at 24 months, and $84 \%$ at 36 months. There were no significant differences in baseline characteristics between participating subjects and those who had withdrawn from the study at any of these assessments (see the companion article by Jensen et al. in this issue).

The recruitment strategy for LNCG was designed to reflect the local population from which the MTA sample was drawn. The LNCG children were randomly selected from the same schools and grades and in the same gender proportions as the MTA children. ADHD diagnosis was neither an inclusion nor exclusion for the LNCG, but the assessment battery included the Diagnostic Interview Schedule for Children IV (Shaffer et al., 2000), which afforded examination of DSM-IV diagnoses. Otherwise the LNCG had the same entry criteria as the MTA except for age. Because the LNCG was not recruited until 2 years after the MTA subjects, we have data starting at 24 months rather than baseline for this group. At this time, for the LNCG, mean age (SD) was 10.37 (1.08) years (range 8-13 years); at 36 months, mean age (SD) was 11.47 (1.15) years (range $9-15$ years). The age range was broader in the LNCG sample because they were selected by grade, not age, but as with the MTA probands, most LNCG children were 9-12 years at 24 months (94\%) and 10-13 at 36 months (94\%). Mean age did not differ at 24 months $(t[d f=811]=1.04 ; p=.36)$, but the MTA children were slightly older than the LNCG children at 36 months $(t[d f=758]=3.19 ; p=.001)$, due to more difficulty and delay in arranging assessment visits relative to the LNCG. Therefore, we controlled for age in the 36-month MTA-LNCG group comparisons. The percentage of females was similar in the LNCG $(18.7 \%$, $n=54 / 289)$ and MTA samples $\left(19.7 \%, n=114 / 579, \chi^{2}{ }_{1}=0.13\right.$, not significant). The percentage retained at 36 months was $94.5 \%$ $(n=273)$.

\section{Measures}

Delinquency Seriousness Classification. Data for delinquency seriousness emanated from two parent report measures, the Diagnostic Interview Schedule for Children IV-CD Module and the Parent DSM-IV Aggression and Conduct Disorder Rating Scale (American Psychiatric Association, 1994), and two self-report measures, the Self-Reported Antisocial Behavior questionnaire (Loeber et al., 1989) through the 24-month assessment and the Self-Reported Delinquency questionnaire (Elliott et al., 1985) at the 36-month assessment. Using all of the available data and procedures developed by Wolfgang and colleagues (1985) and others (e.g., Lee and Hinshaw, 2004; Loeber et al., 1991, 1998), participants were assigned a delinquency classification code at each assessment point (baseline and 14, 24, and 36 months). Items contributing to each code were selected to replicate the coding scheme used in the Pittsburgh Youth Study (Loeber et al., 1991, 1998). Delinquency was coded along an ordinal scale based on the most serious act committed during the past 6 months: $0=$ no delinquency; $1=$ minor delinquency only at home (e.g., theft of less than $\$ 5$ or vandalism); 2 = minor delinquency outside of the home (e.g., vandalism, cheating someone, shoplifting less than $\$ 5) ; 3=$ moderately serious delinquency (e.g., vandalism, theft of $\$ 5$ or more, weapon carrying); 4 = serious delinquency (e.g., breaking and entering, drug selling, attacking someone with the intent to seriously hurt or kill, rape); and $5=$ engagement in two or more different level 4 offenses. Because only a small number of MTA children were coded 5 ( $n=14$ at baseline, $n=4-5$ between 14 and 36 months), we grouped codes 4 and 5 for data analyses, making a five-level ordinal scale of 0 to 4 .

Substance Use Outcomes. Substance use was assessed at 24 and 36 months using a child-reported substance use questionnaire (Molina and Pelham, 2003) adapted for the MTA. The measure included items for lifetime and current (past 6 months) use of licit substances (alcohol, cigarettes, chewing tobacco) and illicit drugs (marijuana and other street drugs). Also included were items for inappropriate or nonprescribed use of medications, including stimulants. The measure was modeled after similar substance use measures in longitudinal or national survey studies of alcohol and other drug use (Donovan, 1994; Jessor et al., 1989; National Household Survey on Drug Abuse, 1992) that also rely on confidential youth self-report as the best source of such data (Winters and Fahnhorst, 2005). As in other studies of young adolescents (Chilcoat and Breslau, 1999), 
TABLE 1

Percentages of MTA and LNCG Children at Each Level of Delinquency Severity at Each Assessment and Percentages With Moderate to Serious Delinquency

\begin{tabular}{|c|c|c|c|c|c|c|c|}
\hline & \multicolumn{5}{|c|}{ Percentage (No.) of Children at Each Level of Delinquency Severity } & \multirow{2}{*}{$\begin{array}{l}\text { \% (No.) With } \\
\text { Moderate to } \\
\text { Serious } \\
\text { Delinquency } \\
\text { (Codes 3-5) }\end{array}$} & \multirow[b]{2}{*}{$\mathrm{OR}, \chi^{2}{ }_{1}, p$} \\
\hline & 0 & 1 & 2 & 3 & $4-5$ & & \\
\hline \multicolumn{8}{|l|}{ Baseline } \\
\hline MTA $(n=579)$ & $23.5(136)$ & $15.2(88)$ & $32.0(185)$ & $11.9(69)$ & $17.4(101)$ & $29.36 \%(170)$ & \\
\hline \multicolumn{8}{|l|}{$14 \mathrm{mo}$} \\
\hline $\operatorname{MTA}(n=538)$ & $36.4(196)$ & $20.1(108)$ & $23.2(125)$ & $9.7(52)$ & $10.6(57)$ & $20.26 \%(109)$ & \\
\hline \multicolumn{8}{|l|}{$24 \mathrm{mo}$} \\
\hline MTA $(n=524)$ & $35.5(186)$ & $21.4(112)$ & $23.3(122)$ & $11.3(59)$ & $8.6(45)$ & $19.85 \%(104)$ & $3.16,25.07, p=.000$ \\
\hline LNCG $(n=289)$ & $61.6(178)$ & $18.0(52)$ & $13.1(38)$ & $3.5(10)$ & $3.8(11)$ & $7.27 \%(21)$ & \\
\hline \multicolumn{8}{|l|}{$36 \mathrm{mo}$} \\
\hline MTA $(n=487)$ & $40.2(196)$ & $14.2(69)$ & $18.5(90)$ & $17.5(85)$ & $9.6(47)$ & $27.10 \%(132)$ & $4.51,{ }^{a} 35.04, p=.000$ \\
\hline LNCG $(n=272)$ & $72.1(196)$ & $11.0(30)$ & $9.6(26)$ & $5.1(14)$ & $2.2(6)$ & $7.35 \%(20)$ & \\
\hline
\end{tabular}

Note: 0 = no delinquency, $1=$ minor delinquency at home (e.g., minor theft or vandalism), $2=$ minor delinquency outside home, $3=$ moderate delinquency (e.g., nonminor theft, weapon carrying, gang fighting), 4-5 = serious delinquency (e.g., forcible theft, breaking and entering, assault).

${ }^{a}$ Statistics are taken from logistic regression in which age at 36 months is statistically controlled. MTA = Multimodal Treatment Study of Children With ADHD; LNCG = local normative comparison group.

substance use was analyzed as a dichotomous variable indicating lifetime use (no/yes) of alcohol (had own drink, not just a sip or taste of another's), tobacco (smoked a cigarette or tried chewing tobacco), or any of the remaining substances, by the 24- and 36-month assessments.

Medication Status. Parents completed the Services Use in Children and Adolescents-Parent Interview (Hoagwood et al., 2004; Jensen et al., 2004) at each assessment. From this measure, prescription medication use was defined as the percentage of days that children received any stimulant or nonstimulant medication for ADHD during the interval since the previous assessment: mean (SD) 0.54 $(0.37)$ at 14 months, $0.56(0.41)$ at 24 months, and $0.56(0.44)$ at 36 months for the MTA children. (This variable is also used in the companion articles in this issue by Jensen et al. and Swanson et al.)

\section{Statistical Approach}

Chi-square tests and logistic regression (to control for age differences at 36 months) were used to compare delinquency and substance use between the MTA and LNCG groups. To examine treatment effects on these outcomes, we used mixed-effects ordinal growth models (e.g., Hedeker and Gibbons, 1994) with the MTA sample, modeling delinquency seriousness (5-level ordinal variable) over 4 assessment points (baseline and 14, 24, and 36 months). This analysis tested whether baseline variables (treatment group assignment) predicted rate of change in delinquency and whether changes in ongoing medication treatment were associated with changes in delinquency over time. Analyses were conducted in MPlus (Ver. 3.2) (Muthén and Muthén, 2004), which provides a maximum likelihood estimator with robust standard errors and missing data estimation. Following previous papers (e.g., companion article in this issue by Jensen et al.), the effect of treatment was tested using three orthogonal contrasts: $\mathrm{Comb}+\mathrm{MedMgt}$ versus $\mathrm{Beh}+\mathrm{CC}$, the MTA Medication Algorithm effect; Comb versus MedMgt, the multimodality effect; and Beh versus CC, the behavioral substitution effect as fixed effects. We separately tested an alternate set of orthogonal contrasts to determine whether intensive behavior therapy affected delinquency and substance use $(\mathrm{Comb}+\mathrm{Beh}$ versus MedMgt+CC, intensive behavioral effect); whether the addition of medication to behavioral therapy was superior to Beh alone (Comb versus Beh, the medication-addition effect); and whether intensive medication management was superior to community care, in which approximately two thirds of children were medicated (MedMgt versus CC, intensity-of-medication effect). In all models selfselected prescription medication use was treated as a time-varying covariate. Site effects were controlled as time-invariant effects. To test the effects of treatment and of delinquency seriousness on 24month and 36-month substance use, the two binary substance use variables were added to the growth model as time-varying dependent variables conditioned on site, the delinquency growth factors (intercept, linear, and quadratic growth factors), and treatment (both invariant and time varying). Finally, to determine whether there were latent subpopulations described by different delinquency growth patterns, a growth mixture model (see Muthén et al., 2002) was tested (see pertinent results for further explanation). Model selection criteria were based on the Bayesian information criterion (see Schwarz, 1978), which permits comparison of the goodness of fit of nonnested models. Lower absolute values indicate better model fit to the data.

\section{RESULTS}

\section{Level of Delinquency for the MTA and LNCG}

Table 1 shows the percentages of MTA and LNCG children at each level of delinquency seriousness for all 
TABLE 2

Percentages of MTA and LNCG Children With Moderate to Serious Delinquency and Substance Use, Separately by Sex

\begin{tabular}{|c|c|c|c|}
\hline & MTA \% (No.) & LNCG \% (No.) & OR, $\chi^{2}{ }_{1}^{2},{ }^{a} p$ \\
\hline \multicolumn{4}{|l|}{ Delinquency at 24 mo } \\
\hline Boys $(N=417$ MTA, 235 LNCG $)$ & $20.9(87)$ & $8.5(20)$ & $2.85,15.81, p=.000$ \\
\hline Girls $(N=107$ MTA, 54 LNCG $)$ & $15.9(17)$ & $1.9(1)$ & $10.50,5.04, p=.025$ \\
\hline \multicolumn{4}{|l|}{ Delinquency at $36 \mathrm{mo}$} \\
\hline Boys $(N=385$ MTA, 218 LNCG $)$ & $29.6(114)$ & $8.3(18)$ & $4.51,30.81, p=.000$ \\
\hline Girls $(N=102$ MTA, 54 LNCG) & $17.6(18)$ & $3.7(2)$ & $5.57,4.97, p=.026$ \\
\hline \multicolumn{4}{|l|}{ Substance use by $24 \mathrm{mo}$} \\
\hline Boys $(N=385$ MTA, 233 LNCG $)$ & $12.2(47)$ & $5.2(12)$ & $2.63,8.20, p=.004$ \\
\hline Girls $(N=101$ MTA, 54 LNCG) & $9.9(10)$ & $7.4(4)$ & $1.39,0.28, p=.597$ \\
\hline \multicolumn{4}{|l|}{ Substance use by $36 \mathrm{mo}$} \\
\hline Boys $(N=377$ MTA, 216 LNCG $)$ & $18.6(70)$ & $7.9(17)$ & $2.53,10.39, p=.001$ \\
\hline Girls $(N=101$ MTA, 53 LNCG $)$ & $12.9(13)$ & $7.5(4)$ & $1.63,0.65, p=.420$ \\
\hline
\end{tabular}

Note: MTA = Multimodal Treatment Study of Children With ADHD; LNCG = local normative comparison group.

${ }^{a}$ Statistics are taken from logistic regressions in which age at follow-up is statistically controlled.

assessment points (recall that the LNCG began at the 24-month assessment). Following established practice (Lee and Hinshaw, 2004), the right side of Table 1 shows the percentages of children with either moderate (code 3) or serious (codes 4-5) delinquency at each of the assessments, separately for the MTA and LNCG children.

Across all of the assessments, most of the MTA children were not engaging in high levels of delinquency. Less than one third of the MTA sample was characterized by moderate to serious delinquency. A general trend was visible such that moderate to serious delinquency decreased from baseline to the 24-month assessment (10 months after treatment ended) but then increased by the 36-month assessment. Behaviors most commonly endorsed by MTA children or their parents and that resulted in a code of $3+$ included stealing without confrontation of the victim (e.g., shoplifting, stealing from someone's desk or locker); hitting that resulted in the victim being cut, bleeding, being knocked unconscious, or being hospitalized; carrying a hidden weapon such as a knife or gun; and using a weapon such as a bat or brick that caused serious harm. As expected with the ages of the children in this study, the most egregious delinquent acts, such as forced sexual behavior, were rarely or never endorsed.

More MTA than LNCG youth had engaged in moderate to serious levels of delinquency by the 24- and 36-month assessments (right side of Table 1). These group differences were also evident when examined separately by sex (Table 2 ).
There was appreciable overlap with CD diagnosis, but a large number of children were coded as delinquent at baseline without having been diagnosed with $\mathrm{CD}$ at baseline: specifically, 66.7\% (56/84) of children with CD had moderate to serious delinquency, but only $32.9 \%(56 / 170)$ of children with moderate to serious delinquency had CD $\left(\chi^{2}{ }_{1}=59.82, p=.000, n=\right.$ 579). This pattern was also evident for CD diagnosis and moderate to serious delinquency assessed at the 36month follow-up: $80.6 \%$ (25/31) and 18.9\% (25/132), respectively $\left(\chi_{1}^{2}=41.07, p=.000, n=480\right.$. Thus, although CD diagnosis was strongly and significantly correlated with delinquency and baseline CD predicted moderate to serious delinquency at 36 months $\left(\chi^{2}{ }_{1}=\right.$ $26.16, p=.000$, odds ratio $[\mathrm{OR}]=3.83, n=487)$, most children with delinquent behavior were not diagnosed with CD. This finding probably emanates from the requirement in DSM-IV (American Psychiatric Association, 1994) that three or more behaviors be exhibited for CD diagnosis, whereas the delinquency severity code is affected by severity and not number of behaviors (except for level 5 of the coding scheme, which occurred infrequently). It could be argued that the high threshold for a diagnosis of $\mathrm{CD}$ is stringent and that the presence of ODD is a more sensitive indicator. We did find that presence of either ODD or CD at baseline predicted moderate to serious delinquency at 36 months, $\chi^{2}{ }_{1}=$ 7.03, $p=.008, n=471$ ), but the magnitude of effect (OR 1.76) was less than that found for prediction from baseline CD. Specifically, 32.1\% $(n=86)$ of the 268 children with ODD or CD at baseline had moderate 
to serious delinquency at 36 months, whereas $52.7 \%$ $(n=39)$ of the 74 children with CD at baseline had moderate to serious delinquency at 36 months. (Note that analysis of ODD alone is not possible because, per DSM-IV and the Diagnostic Interview Schedule for Children diagnosing algorithm, CD diagnosis takes precedence over ODD diagnosis.)

\section{Substance Use Among the MTA and LNCG Children}

At 24 and 36 months, there were statistically significant MTA-LNCG group differences in substance use, with $11.7 \%$ of the MTA children (57/486) versus $5.6 \%$ of the LNCG (16/287) reporting lifetime use of any substance by 24 months (OR 2.25, $\chi^{2}{ }_{1}=8.58 ; p=$ $.003)$ and $17.4 \%$ of the MTA children (83/478) versus $7.8 \%$ of the LNCG $(21 / 269)$ reporting lifetime use by 36 months (OR 2.34, Wald $\chi^{2}{ }_{1}=10.63 ; p=.001$ ) after controlling for age. By 36 months substances that had been used were mostly alcohol $(8.4 \%$ of MTA, $2.6 \%$ of LNCG; $p=.005)$ and cigarettes $(11.1 \%$ of MTA, 3.3\% of LNCG; $p=.001)$ with a small number of MTA children having tried marijuana $3.0 \%$ of MTA, $0 \%$ of LNCG). Of 40 MTA children who had consumed alcohol, 8 reported no alcohol in the past 6 months, 17 drank once or twice, and 11 drank more frequently (4 subjects were missing data); 18 reported drinks 5 or more times in their lifetime. Of 53 MTA children who had smoked cigarettes, 24 had smoked more than once and 7 were smoking 1 or more cigarettes per day. There was statistically significant overlap in use: $45.0 \%(18 / 40)$ of MTA children who had consumed alcohol had smoked a cigarette, and $34.0 \%(18 / 53)$ of MTA children who had smoked a cigarette had consumed alcohol $\left(\chi_{1}^{2}=33.96 ; p=.000\right)$. Significant MTA-LNCG group differences in substance use were evident for boys but not for girls (Table 2).

To test whether MTA-LNCG group differences in substance use occurred after controlling for delinquency, the percentages of MTA and LNCG youths reporting substance use were compared within two delinquency subgroups: those with moderate to serious delinquency and those without moderate to serious delinquency. For youths with moderate to serious delinquency, MTALNCG group differences were not significant at 24 months (23.5\% vs. $19.0 \%$, respectively, Wald $\chi_{1}^{2}=0.09$, $p=.762$, OR 1.21$)$ or at 36 months $(30.0 \%$ vs. $31.6 \%$, Wald $\chi_{1}^{2}=0.07, p=.793$, OR 0.87). However, for youths without moderate to serious delinquency, more
MTA than LNCG children reported substance use at 24 months (8.6\% vs. $4.5 \%$, Wald $\chi^{2}{ }_{1}=3.92, p=.048$, OR 1.99$)$ and at 36 months $(12.6 \%$ vs. $6.0 \%$, Wald $\chi_{1}^{2}=6.06, p=.014$, OR 2.16; the latter effects were found controlling for age).

\section{Association Between Treatment and Delinquency}

The longitudinal pattern of delinquency seriousness for the MTA children, estimated from the random effects ordinal growth model, was quadratic. This shape was characterized by decreasing delinquency seriousness from baseline to 24 months and increasing delinquency seriousness between 24 and 36 months, mirroring the observed data in Table 1. Although there was variability across subjects in the initial level of delinquency seriousness, there was little variability across subjects in the rate of change (slope) in delinquency over time ( $p=.40$ for linear change, $p=.08$ for quadratic change).

There were no statistically significant effects at the $p<.05$ level of randomly assigned treatment on individual's rate of change in delinquency between baseline and 36 months, tested either with the original or with the alternate sets of orthogonal treatment contrasts (Table 3).

Prescribed medication use and delinquency seriousness were not associated at 14 months (0.01 [0.24]; $p=.98)$, but they were associated at 24 months (0.63 [0.23]; $p=.005)$ and at 36 months (0.62 [0.29]; $p=.034)$. Thus, children with higher delinquency scores at 24 and 36 months were more likely to have been medicated for ADHD in the past year. These figures are unstandardized parameter estimates similar to unstandardized regression coefficients, with SEs in brackets, for the associations between prescription medication use and delinquency seriousness. These results were equivalent across the two models with different orthogonal treatment contrasts.

To test whether randomly assigned treatment predicted level of delinquency seriousness at 14 months, as opposed to slope (rate of change in delinquency), the zero time score for the slope growth factor was rescaled to the 14-month time point (Muthén and Muthén, 2004). No statistically significant effects of randomly assigned treatment (for the original or alternate set of treatment contrasts) resulted for this reanalysis or for rescaling the zero time score to the 24- and 36-month time points. Thus, within the delinquency growth model, randomly assigned 


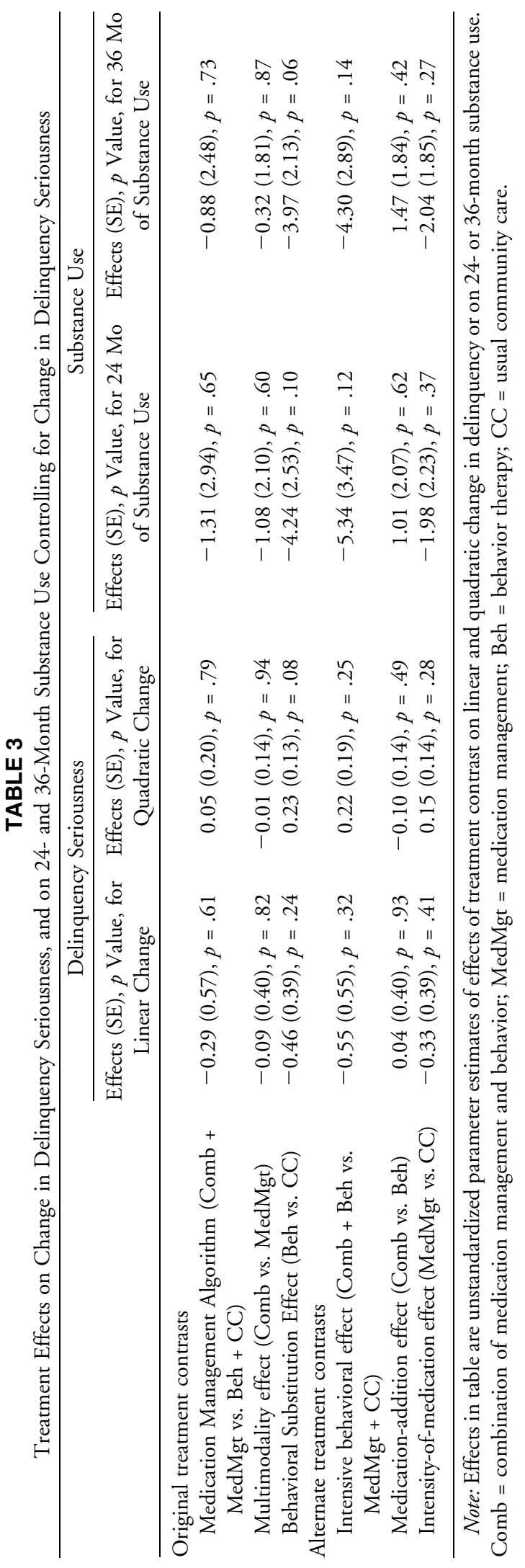

treatment did not predict level of delinquency attained by 14, 24, or 36 months. As expected from this finding, the percentages of children with moderate to serious delinquency at 14 months were not appreciably different across the treatment groups: $23.44 \%$ (30/128) for MedMgt, 20.15\% (27/134) for CC, $19.57 \%(27 / 138)$ for Comb, and $18.12 \%(25 / 138)$ for Beh.

The growth mixture model analysis ruled out the possibility of subgroups with differing patterns of delinquency seriousness over time. There was no evidence of latent subclasses (i.e., the single class model had the lowest Bayes information criterion of 6,270.92 vs. 6,292.17 and 6,285.04 for two- and threeclass models, respectively).

\section{Association Between Treatment and Substance Use}

In the second growth model we examined the effects of randomized treatment and prescription medication use on 24-month and 36-month substance use (new or continuing use since 24 months) by adding these variables to the delinquency growth model. Neither the original nor the alternate sets of orthogonal treatment contrasts were significantly related to 24 - or 36-month substance use, although there were marginally significant $p$ values for the behavioral substitution and intensive behavioral effects at 24 and 36 months (Table 3). Prescription medication use was not significantly associated with 24-month substance use (0.35 [0.49]); $p=.47)$, nor with 36-month substance use $(0.40[0.39] ; p=.30)$.

Youths randomly assigned to behavior therapy had somewhat lower rates of 36-month substance use than the youths in the MedMgt and CC conditions: $21.9 \%$ (25/114) for MedMgt, $19.0 \%$ (22/116) for CC, $16.0 \%$ (20/125) for Comb, and 13.0\% (16/123) for Beh. We considered the possibility that the tests of treatment effects on substance use in the delinquency growth model, which required treatment effects above and beyond growth in delinquency, were overly stringent. Thus, we also tested treatment effects on substance use using logistic regressions of substance use (by 24 or 36 months) on the orthogonal treatment contrasts (original or alternate), controlling for baseline delinquency only and site and using missing data estimation. Through this analysis, we found that children who received intensive behavior therapy $($ Beh+Comb) fared better by 24 months than the 
children who did not (MedMgt+CC) $(-1.38$ [0.60]; $p=.02]$. This effect was no longer significant by 36 months $(-0.86[0.54] ; p=.11)$.

For the same reason (i.e., potential for overly stringent test), we tested simple bivariate associations between prescribed medication use and substance use. No associations were found at 24 months $(p=.39)$ or at 36 months $(p=.59)$. Age and prescription medication use were not significantly associated at 24 months $(r=$ $-0.07 ; p=.11)$ or at 36 months $(r=-0.04 ; p=.40)$ ruling out age as a confounder in the association (or lack thereof) between prescribed medication use and substance use in these analyses.

\section{Association Between Delinquency and Substance Use}

From the second growth model, delinquency at baseline significantly predicted substance use at 24 months (0.92 [0.28]; $p=.00)$ and at 36 months $(0.53$ [0.17]; $p=.00)$, such that children with more serious delinquent behavior at baseline were more likely to report substance use by 24 and 36 months. The linear growth factor for delinquency was marginally associated with substance use at 24 months $(-4.48$ [2.54]; $p=.08)$ and at 36 months $(-3.24$ [1.83]; $p=.08)$; the quadratic growth factor for delinquency was marginally associated with substance use at 24 months (5.78 [3.11]; $p=.06$ ), and significantly associated with substance use at 36 months (7.55 [2.97]; $p=.01$ ). (Again, these figures are unstandardized parameter estimates and SEs are in brackets.) The latter result suggests the possibility that increasing delinquency between 24 and 36 months was associated with an increase in substance use in the same time period. We explored this possibility by comparing the children whose delinquency codes increased between 24 and 36 months to the children whose delinquency codes did not increase between 24 and 36 months, on initiation of substance use. Indeed, there was more substance use initiation in the former $(13.9 \%)$ than in the latter $(6.4 \%)$ group $\left(\chi^{2}{ }_{1}=6.86\right.$; $p=.009$, OR 2.37), supporting this interpretation.

We tested baseline CD as a predictor of substance use using logistic regressions of substance use by 24 months or new/continuing substance use by 36 months on CD in addition to the orthogonal treatment contrasts and site, using missing data estimation. Baseline CD did not predict 24-month $(0.54[0.34] ; p=.12)$ nor 36-month (0.56 [0.33]; $p=.08)$ substance use. However, the presence of ODD or CD (56.3\% of MTA children) predicted 24-month substance use (0.60 [0.30]; $p=$ $.04)$, but not 36 months substance use (0.30 [0.27]; $p=.26$ ). Reported as an odds ratio, the MTA children with ODD or CD at baseline were 1.83 times more likely to report substance use by 24 months.

In summary, baseline delinquency seriousness and growth in delinquency seriousness predicted 24- and 36-month substance use, baseline ODD or CD diagnosis predicted 24-month but not 36-month substance use, and baseline CD did not predict 24- or 36-month substance use.

\section{DISCUSSION}

We found that the majority of the MTA children were not seriously delinquent or were not experimenting prematurely with alcohol, tobacco, or illicit drugs by the 36-month assessment when most participants were 11 to 13 years old. Nevertheless, these behaviors were more prevalent among the MTA than LNCG children, with more than one fourth of the probands evidencing moderate or serious delinquency by the 36-month follow-up. The time course was quadratic: there was a significant decrease in delinquent behavior between baseline and 24 months (the treatment phase plus 10 months posttreatment) followed by an increase in delinquency between 24 and 36 months. A simultaneous related increase in substance use from 24 to 36 months suggests the need for continued study of both behaviors into adolescence for the MTA children. Children who received intensive behavior therapy (Beh+Comb) reported less substance use by 24 months than the children who did not (MedMgt+CC). There were no other effects of initial treatment assignment (MedMgt, Beh, Comb, or CC) on growth in delinquency over time, level of delinquency seriousness posttreatment, or substance use by the 24and 36-month follow-ups. Self-selected prescription medication treatment after 14 months was positively related to delinquency seriousness: children with more serious offenses were more likely to be medicated after the end of study-delivered treatment. No association was observed for early substance use.

In a companion article in this issue by Jensen et al., it was reported that by the 36-month follow-up (22 months posttreatment) the children in the MTA could no longer be discriminated by their original randomized treatment assignments, but on average they had 
maintained some of the gain made by 14 months for ADHD and ODD symptoms, social skills, and overall impairment. Children in the Beh and CC groups maintained their posttreatment gains to 36 months, and children in the MedMgt and Comb groups lost their relative posttreatment advantage but maintained gains commensurate with those attained by Beh or CC. It was also reported in the companion article in this issue by Swanson et al. (2007) that the ADHD and ODD symptom ratings for the children in the MTA were worse than those for the LNCG at the 36-month followup, which mirrors previous reports (Swanson et al., 2001). Thus, the finding herein that delinquency decreased during the active treatment phase, yet remained significantly higher for the MTA than LNCG children by 24 and 36 months, mirrors the general findings. The percentages of MTA youths with moderately serious delinquent behavior (e.g., $27 \%$ at 36 months) were lower than reported by Loeber et al. (1998) for similar-age urban boys in Pittsburgh (42\%-54\%), but they are in the literature-suggested range from other longitudinal studies of children with ADHD. Those figures range from $25 \%$ by age 13 (Weiss and Hechtman, 1993) to $44 \%$ by age 15 (Barkley et al., 1990). Thus, although the majority of the MTA children with ADHD did not exhibit delinquent behavior, we did see in a subset an expected developmental unfolding of earlier behavior problems into more serious delinquent behavior (see Loeber et al., 1991 for expected increases in delinquency between first grade and age 14). We will be able to test in future studies whether persistence of ADHD and ODD symptoms throughout treatment and posttreatment is important for the development of delinquency in adolescence (e.g., see Lahey et al., 2000).

It is disappointing that the intensive state-of-the-art MTA treatments did not lead to a more rapid deceleration in delinquency beyond that of CC, although this makes statistical sense given the lack of variability in delinquency slopes over time across the children in the study. Why did treatment group assignment fail to predict absolute level of delinquency at 14 months and thereafter, then? This is puzzling because our previous analyses (Hechtman et al., 2005; The MTA Cooperative Group, 1999a) reveal significant reductions in ODD symptoms and diagnosis as a result of study-managed medication, and ODD symptoms/ diagnosis are strongly predictive of delinquency onset and persistence (Lahey et al., 2000; Lee and Hinshaw, 2004). Theoretically, medication management should have decreased delinquency through its effect on ODD. Moreover, because improving parenting effectiveness is a key ingredient in effective delinquency treatments (Patterson et al., 1992), the combination of medication and behavior therapy should have decreased delinquency because of its effects on negative ineffective as well as constructive parenting (Wells et al., 2000, 2006). One speculation, which follows our previous report that about half of the sample remained symptomatic for both ADHD and ODD symptoms (Swanson et al., 2001), is that different psychosocial treatment packages are necessary to effect change for those treatment-resistant children. These symptom-persistent children probably overlap with the delinquent children identified in this article, all of whom may need enhanced or prolonged interventions beyond the regimen of behavior therapy provided in the MTA (for review, see Pelham and Fabiano, in press).

Significant prescription medication effects were only found after 14 months (after the end of study-delivered treatments) and appeared to be reactive, with more selfselected medication treatment associated with more serious delinquency. This finding parallels our results reported in the companion article by Jensen et al. in this issue, in which more medication use and more special educational services were associated with deterioration in ADHD symptoms. Taken together with our companion paper findings that preexisting subject characteristics do not explain the absence of beneficial medication treatment effects at 36 months (Swanson et al., 2007), these findings suggest the possibility that prolonged medication, perhaps delivered in response to chronic and serious problem behavior, may not be efficacious. Because these findings rest on observed associations in our data rather than experimentally controlled use of medication long-term, our findings do not rule out the possibility that behavior would be worse without medication.

Our finding of elevated substance use among the MTA children extends earlier findings of ADHD risk to a younger age than has been previously reported. As expected at 11 to 13 years of age, group differences were principally attributable to low level but precocious use of alcohol and/or tobacco. Also as expected, substance use was strongly (but not completely) associated with severity of delinquency, and it was prospectively 
predicted by delinquency seriousness (less well predicted by ODD or CD diagnosis at baseline). Previous studies finding no group differences in any lifetime use of alcohol (which includes first drink) were almost always studies of older adolescents beyond the age of 14 and up to the early 20s (Barkley et al., 1990; Hartsough and Lambert, 1987; Molina and Pelham, 2003). At these older ages, light drinking is developmentally normative and not likely to differentiate youths with ADHD from those without this diagnosis. When heavier levels of alcohol use (e.g., frequency of drunkenness, alcohol-related problems) are examined in mid- to late adolescence, $\mathrm{ADHD} /$ non-ADHD differences do emerge (Molina and Pelham, 2003; Molina et al., 2007). Previous studies have suggested earlier ages of tobacco initiation for youths with ADHD (Milberger et al., 1997; Molina and Pelham, 2003). Thus, although small numbers of MTA youths are endorsing substance use, the higher rate of this initial use at a young age compared with classmate controls suggests that clinical concern is warranted. This interpretation follows from the well-established association between early initiation into substance use and later problematic use of drugs and alcohol (e.g., Grant and Dawson, 1997).

We did not find evidence of protective or adverse effects of medication treatment for ADHD, either study delivered or self-selected, on the initiation of substance use at this young age. This null finding has been previously reported for roughly this age range, in the Chilcoat and Breslau (1999) sample at age 11, and in the Developmental Trends Study for boys 13 to 15 years old (Burke et al., 2001). This finding does not negate the possibility of associations either positive or negative later in adolescence (Barkley et al., 2003; Biederman et al., 1999) or in adulthood (Barkley et al., 2003; Pelham et al., 2005; Lambert and Hartsough, 1998; Loney et al., 2002). Whether an association exists (protective or predisposing) remains highly controversial and not well studied in samples sufficiently large that confounding variables can be effectively controlled. Protective effects are presumed to occur through a reduction in risk factors contributing to substance use vulnerability (e.g., reduction in ADHD or ODD/CD symptoms) or a decreased need for self-medication (Khantzian, 1997; Wilens et al., 2003) and adverse effects are presumed to occur via processes such as behavioral sensitization (Lambert and Hartsough, 1998; Pelham et al., 2005) or training children to rely on drug use as a coping strategy (Henker et al., 1981). Given these conflicting arguments and the accumulating longitudinal data on the MTA children into adolescence, a crucial objective of this group is to examine the extent to which ongoing psychoactive medication treatment is associated with the further development of substance use and associated problems at older ages.

Children who received intensive behavior therapy (Comb+Beh) reported less substance use by 24 months than the children who received intensive medication management or community care (MedMgt+CC), which suggests enduring effects of behavior therapy on an important clinical outcome 1 year after treatment ended. We can only speculate whether the effect would have endured through 36 months if maintenance behavioral treatment had been provided. It is unclear what variables might be accounting for this effect given the lack of behavior therapy effects on a select set of outcomes as tested with the original treatment contrasts at 24 months (The MTA Cooperative Group, 2004a). Nevertheless, this result is encouraging, and it suggests the importance of continued investigation into the range of variables that may propel escalation or maintenance of substance use (for review, see Chassin et al., 2004; Kandel and Yamaguchi, 2002). Following this line of thinking, it will be important in future studies to test the wide range of intraindividual difference variables (e.g., ADHD and ODD symptom severity and persistence, cognitive variables, social skills), family factors (e.g., parental substance abuse and antisociality, parenting effectiveness), and socioenvironmental variables (e.g., peer and sibling behavior and substance use, neighborhood influences) that, in addition to treatment and conduct problems, may affect the initiation and course of substance use in the MTA children.

\section{Limitations}

First, although generalizability of these multisite findings should be better than from single-site studies, it is important to recall that participants were required to have Combined type ADHD. Thus, conclusions may not be generalizable to the Inattentive subtype of ADHD, which may be qualitatively different (Milich et al., 2001). Second, our measure of delinquency seriousness is an improvement over simple count 
variables (e.g., adding up the number of disparate behaviors endorsed), but we cannot rule out the possibility that different results would emerge from alternative scoring algorithms. Third, the young age of our sample may have precluded detection of differential treatment effects on delinquency. Greater variability in this outcome appears to be emerging at older ages. Although even more delayed effects of treatment on delinquency are not expected, further study of the sample into adolescence will allow more finely grained analyses of the simultaneous development of specific delinquent behaviors and substance use. Finally, an important caveat regarding our ability to test effects of ongoing (self-selected) treatment was our consideration of only prescribed medication treatment and not psychosocial treatments; the latter are difficult to study because of measurement challenges.

\section{Clinical Implications}

Most of the MTA children were not engaging in delinquent behaviors or experimenting with alcohol, tobacco, or other illicit drugs by 11 to 13 years of age. However, our finding that the MTA children were at increased risk of delinquency and early substance use 2 years after intensive pharmacological and/or behavioral treatment underscores the need for continuous monitoring of these outcomes as the children enter adolescence. Parents of children with ADHD should be informed about this risk, and strategies to improve parental monitoring (Chilcoat and Breslau, 1999; Molina et al., 2005) and minimize negative peer influences (Marshal et al., 2003) implemented.

The Multimodal Treatment Study of Children with ADHD (MTA) was a National Institute of Mental health (NIMH) cooperative agreement randomized clinical trial involving six clinical sites. Collaborators from the National Institute of Mental Health: Peter S. Jensen, M.D. (currently at Columbia University, New York), L. Eugene Arnold, M.D., M.Ed. (currently at Ohio State University), Joanne B. Severe, M.S. (Clinical Trials Operations and Biostatistics Unit, Division of Services and Intervention Research), Benedetto Vitiello, M.D. (Child \& Adolescent Treatment and Preventive Interventions Research Branch), Kimberly Hoagwood, Ph.D. (currently at Columbia University); previous contributors from NIMH to the early phase: John Richters, Ph.D. (currently at National Institute of Nursing Research); Donald Vereen, M.D. (currently at National Institute on Drug Abuse). Principal investigators and co-investigators from the clinical sites are University of California, Berkeley/San Francisco: Stephen P. Hinshaw, Ph.D. (Berkeley), Glen R. Elliott, M.D., Ph.D. (San Francisco); Duke University: C. Keith Conners, Ph.D., Karen C.
Wells, Ph.D., John March, M.D., M.P.H., Jeffery Epstein, Ph.D.; University of California, Irvine/Los Angeles: James Swanson, Ph.D. (Irvine), Dennis P. Cantwell, M.D. (deceased, Los Angeles), Timothy Wigal, Ph.D. (Irvine); Long Island Jewish Medical Center/Montreal Children's Hospital: Howard B. Abikoff, Ph.D. (currently at New York University School of Medicine), Lily Hechtman, M.D. (McGill University, Montreal); New York State Psychiatric Institute/Columbia University/Mount Sinai Medical Center, New York: Laurence L. Greenhill, M.D. (Columbia University), Jeffrey H. Newcorn, M.D. (Mount Sinai School of Medicine); University of Pittsburgh: William E. Pelham, Ph.D. (currently at State University of New York, Buffalo), Betsy Hoza, Ph.D. (currently at University of Vermont, Burlington), Brooke Molina, Ph.D. Original statistical and trial design consultant: Helena C. Kraemer, Ph.D. (Stanford University). Follow-up phase statistical collaborators: Robert D. Gibbons, Ph.D. (University of Illinois, Chicago), Sue Marcus, Ph.D. (Mt. Sinai School of Medicine), Kwan Hur, Ph.D. (University of Illinois, Chicago). Kate Flory, Ph.D. (University of South Carolina at Columbia). Andrew Greiner, B.S. (State University of New York at Buffalo). Collaborator from the Office of Special Education Programs/U.S. Department of Education: Thomas Hanley, Ed.D. Collaborator from Office of Juvenile Justice and Delinquency Prevention/ Department of Justice: Karen Stern, Ph.D.

Disclosure: During the course of the MTA, since 1992: Dr. Hinshaw has consulted to Noven and Sigma Tau and has been on the speakers' bureau of McNeil. Mr. Greiner has consulted to Comprehensive Treatment for ADHD, Inc., the Research Foundation of the State University of New York, and the Clinical Trials Coordination Center of the University of Rochester Medical Center. Dr. Arnold has received research funding from Celgene, Shire, Noven, Eli Lilly, Targacept, Sigma Tau, and Novartis; has consulted to Shire, Noven, Sigma Tau, Ross, and Organon; and has been on the speakers' bureaus of Abbott, Shire, McNeil, and Novartis. Dr. Swanson has received research support from Alza, Richwood, Shire, Celgene, Novartis, Celltech, Gliatech, Cephalon, Watson, CIBA, Janssen, and McNeil; has been on the advisory boards of Alza, Richwood, Shire, Celgene, Novartis, Celltech, UCB, Gliatech, Cephalon, McNeil, and Eli Lilly; has been on the speakers' bureaus of Alza, Shire, Novartis, Celltech, UCB, Cephalon, CIBA, Janssen, and McNeil; and has consulted to Alza, Richwood, Shire, Celgene, Novartis, Celltech, UCB, Gliatech, Cephalon, Watson, CIBA, Janssen, McNeil, and Eli Lilly. Dr. Hechtman has received research funding from the National Institute of Mental Health, Eli Lilly, GlaxoSmithKline, Janssen-Ortho, Purdue Pharma, and Shire; has been on the speakers' bureaus of the National Institute of Mental Health, Eli Lilly, Janssen-Ortho, and Shire; and has been on the advisory boards of Eli Lilly, Janssen-Ortho, Purdue Pharma, and Shire. Dr. Jensen has received research funding from McNeil and unrestricted grants from Pfizer; has consulted to Best Practice, Inc., Shire, Janssen, Novartis, and UCB; and has participated on the speakers' bureaus of Janssen-Ortho, Alza, McNeil, UCB, CME Outfitters, and the Neuroscience Education Institute. Dr. Vitiello has consulted to Richwood Pharmaceuticals. Dr. Hoza has received research funding from MediaBalance, Inc. and support for educational conferences from Abbott Laboratories. Dr. Pelham has received research funding from Alza, Shire, Noven, Eli Lilly, and Cephalon; has served on advisory boards of or has consulted to Alza/McNeil Richwood/Shire, Noven, Eli Lilly, Cephalon, Novartis, Celgene, and Abbott; and has been on the speakers' bureaus of Shire, and McNeil. Dr. Elliott has received research funding from Cephalon, McNeil, Shire, Sigma Tau, 
and Novartis; has consulted to Cephalon and McNeil; and has been on the speakers' bureaus of Janssen, Eli Lilly, and McNeil. Dr. Abikoff has received research funding from McNeil, Shire, Eli Lilly, and BristolMyers Squibb; has consulted to McNeil, Shire, Eli Lilly, Pfizer, Celltech, Cephalon, and Novartis; and has been on the speakers' bureaus of McNeil, Shire, and Celltech. Dr. Conners has received research funding from Celgene, Shire, Noven, Eli Lilly, Targacept, and Novartis; has consulted to Celgene, Shire, Novartis, Alza, and Noven; is on the Eli Lilly Advisory Committee, and has been on the speakers' bureaus of Shire, McNeil, and Novartis. Dr. Epstein has received research funding from McNeil, Shire, Eli Lilly, Novartis; has been on the advisory board of Shire; and has been on the speakers' bureaus of Shire and McNeil. Dr. Greenhill has received research funding from or has been on the speakers' bureaus of Eli Lilly, Alza, Shire, Cephalon, $M c N e i l$, Celltech, Novartis, Sanofi Aventis, Otsuka, and Janssen. Dr. March has been a consultant or scientific advisor to or received research funding from Eli Lilly, Pfizer, Wyeth, Jazz, MedAvante, Shire, Cephalon, Organon, McNeil, and AstraZeneca; serves on a DSMB for Organon, Johnson \& Johnson, and AstraZeneca; and holds stock in MedAvante. Dr. Newcorn has received research funding from or has been on the speakers' bureaus of Eli Lilly, Alza, Shire, Celgene, McNeil, Celltech/UCB, Novartis, Sanofi Aventis, Janssen, and Bristol-Myers Squibb. Dr. Wigal has received research funding from Eli Lilly, Shire, Novartis, and McNeil and has been on the speakers' bureaus of McNeil and Shire. The other authors have no financial relationships to disclose.

\section{REFERENCES}

American Psychiatric Association (1994), Diagnostic and Statistical Manual of Mental Disorders, 4th edition (DSM-IV), Washington, DC: American Psychiatric Association

Arnold LE, Abikoff HB, Cantwell DP, Conners CK, Elliott GR, Greenhill LL (1997), NIMH collaborative Multimodal Treatment Study of Children with ADHD (MTA): design challenges and choices. Arch Gen Psychiatry 54:865-870

Arnold LE, Elliott M, Lindsay RL et al. (2005), Gestational and postnatal tobacco smoke exposure as predictor of ADHD, comorbid ODD/CD, and treatment response in the MTA. Clin Neurosci Res 5:295-306

Barkley RA, Fischer M, Edelbrock CS, Smallish L (1990), The adolescent outcome of hyperactive children diagnosed by research criteria: I. An 8-year prospective follow-up study. J Am Acad Child Adolesc Psychiatry 29:546-557

Barkley RA, Fischer M, Smallish L, Fletcher KE (2003), Does the treatment of attention-deficit/hyperactivity disorder with stimulants contribute to drug use/abuse? A 13-year prospective study. Pediatrics 111: 97-109

Biederman J, Wilens T, Mick E, Spencer TJ, Faraone SV (1999), Pharmacotherapy of attention-deficit/hyperactivity disorder reduces risk for substance use disorder. Pediatrics 104:e20

Burke JD, Loeber R, Lahey BB (2001), Which aspects of ADHD are associated with tobacco use in early adolescence? I Child Psychol Psychiatry 42:493-502

Chassin L, Hussong AM, Barrera M, Molina BSG, Trim RS, Ritter J (2004), Adolescent substance use. In: Handbook of Adolescent Psychology, 2nd ed., Lerner RM, Steinberg L, eds. Hoboken, NJ: Wiley, pp 665-696

Chilcoat HD, Breslau N (1999), Pathways from ADHD to early drug use. $J$ Am Acad Child Adolesc Psychiatry 38:1347-1354

Conners CK, Epstein JN, March JS et al. (2001), Multimodal treatment of ADHD in the MTA: an alternative outcome analysis. J Am Acad Child Adolesc Psychiatry 40:159-167

Donovan JE (1994), The Teen Drinking Questionnaire. Pittsburgh: Pittsburgh Adolescent Alcohol Research Center, University of Pittsburgh

Elliott D, Huizinga D, Ageton S (1985), Explaining Delinquency and Drug Use. Beverly Hills, CA: Sage

Gittelman R, Mannuzza S, Shenker R, Bonagura N (1985), Hyperactive boys almost grown up: I. Psychiatric status. Arch Gen Psychiatry 42: 937-947

Grant BF, Dawson DA (1997), Age at onset of alcohol use and its association with DSM-IV alcohol abuse and dependence: results from the National Longitudinal Epidemiologic Survey. J Subst Abuse 9:103-110

Greenhill LL, Abikoff HB, Arnold LE, Cantwell DP, Conners CK, Elliott GR (1996), Medication treatment strategies in the MTA: relevance to clinicians and researchers. J Am Acad Child Adolesc Psychiatry 35: 1304-1313

Greenhill LL, Swanson JM, Vitiello B, Davies M, Clevenger W, Wu M (2001), Impairment and deportment responses to different methylphenidate doses in children with ADHD: the MTA titration. J Am Acad Child Adolesc Psychiatry 40:180-187

Hartsough CS, Lambert NM (1987), Pattern and progression of drug use among hyperactives and controls: a prospective short-term longitudinal study. J Child Psychol Psychiatry 28:543-553

Hechtman L, Etcovitch J, Platt R et al. (2005), Does multimodal treatment of ADHD decrease other diagnoses? Clin Neurosci Res 5:283-294

Hedeker D, Gibbons RD (1994), A random-effects ordinal regression model for multilevel analysis. Biometrics 50:933-944

Henker B, Whalen CK, Blunt-Bugental D, Barker C (1981), Licit and illicit drug use patterns in stimulant-treated children and their peers. In: Psychosocial Aspects of Drug Treatment for Hyperactivity, Gadow KD, Loney J, eds. Boulder, CO: Westview, pp 443-462

Hinshaw SP, Lahey BB, Hart EL (1993), Issues of taxonomy and comorbidity in the development of conduct disorder. Dev Psychopathol 5:31-49

Hinshaw SP, March JS, Abikoff HB, Arnold LE, Cantwell DP, Conners CK (1997), Comprehensive assessment of childhood attention-deficit hyperactivity disorder in the context of a multisite, multimodal clinical trial. J Atten Disord 1:217-234

Hoagwood K, Jensen PS, Arnold LE et al. (2004), Reliability of the Services for Children and Adolescents Parent Interview (SCAPI). J Am Acad Child Adolesc Psychiatry 43:1345-1454

Jensen PS, Arnold LE, Swanson JM et al. (2007), 3-Year follow-up of the NIMH MTA Study. J Am Acad Child Adolesc Psychiatry 46:988-1001

Jensen P, Hoagwood K, Roper M et al. (2004), The Services for Children and Adolescents Parent Interview (SCAPI): development and performance characteristics. I Am Acad Child Adolesc Psychiatry 43:1334-1344

Jensen PS, Hinshaw SP, Kraemer HC, Lenora N, Newcorn JH, Abikoff HB (2001), ADHD comorbidity findings from the MTA Study: comparing comorbid subgroups. J Am Acad Child Adolesc Psychiatry 40:147-158

Jessor R, Donovan JE, Costa FM (1989), Health Behavior Questionnaire. Boulder, CO: Institute of Behavioral Science, University of Colorado

Kandel DB, Yamaguchi K (2002), Stages of drug involvement in the U.S. population. In: Stages and Pathways of Drug Involvement: Examining the Gateway Hypothesis, Kandel DB, ed. New York: Cambridge University Press, pp 65-89

Khantzian EJ (1997), The self-medication hypothesis of substance use disorders: a reconsideration and recent applications. Harv Rev Psychiatry 4:231-244

Lahey BB, McBurnett K, Loeber R (2000), Are attention-deficit/ hyperactivity disorder and oppositional defiant disorder developmental precursors to conduct disorder? In: Handbook of Developmental Psychopathology, Sameroff AJ, Lewis M, Miller SM, eds. New York: Kluwer Academic/Plenum, pp 431-446

Lambert NL, Hartsough CS (1998), Prospective study of tobacco smoking and substance dependencies among samples of ADHD and non-ADHD participants. J Learn Disabil 31:533-544

Lee SS, Hinshaw SP (2004), Severity of adolescent delinquency among boys with and without attention deficit hyperactivity disorder: predictions from early antisocial behavior and peer status. J Clin Child Adolesc Psychol 33:705-716

Lilienfeld SO, Waldman ID (1990), The relation between childhood attention-deficit hyperactivity disorder and adult antisocial behavior reexamined: the problem of heterogeneity. Clin Psychol Rev 10:699-725

Loeber R, Green SM, Keenan K, Lahey BB (1995), Which boys will fare worse? Early predictors of the onset of conduct disorder in a six-year longitudinal study. J Am Acad Child Adolesc Psychiatry 34:499-509 
Loeber R, Stouthamer-Loeber M, Van Kammen WB, Farrnington DP (1989), Development of a new measure of self-reported antisocial behavior for young children: prevalence and reliability. In: Cross-national Research in Self-reported Crime and Delinquency, Klein MW, ed. Boston: Kluwer, pp 203-225

Loeber R, Stouthamer-Loeber M, Van Kammen W, Farrington DP (1991), Initiation, escalation and desistance in juvenile offending and their correlates. J Criminal Law Criminol 82:36-82

Loeber R, Farrington DP, Stouthamer-Loeber M, Van Kammen WB (1998), Antisocial Behavior and Mental Health Problems. Explanatory Factors in Childhood and Adolescence. Mahwah, NJ: Erlbaum

Loney J, Kramer JR, Salisbury H (2002), Medicated vs. unmedicated ADHD children: adult involvement with legal and illegal drugs. In: Attention Deficit Hyperactivity Disorder. State of the Science. Best Practices, Jensen PS, Cooper JR, eds. Kingston, NJ.: Civic Research Institute

Marshal MP, Molina BSG, Pelham WE (2003), Childhood ADHD and adolescent substance use: an examination of deviant peer group affiliation as a risk factor. Psychol Addict Behav 17:293-302

Milberger S, Biederman J, Faraone SV, Chen L, Jones J (1997), ADHD is associated with early initiation of cigarette smoking in children and adolescents. J Am Acad Child Adolesc Psychiatry 36:37-44

Milich R, Balentine AC, Lynam DR (2001), ADHD combined type and ADHD predominately inattentive type are distinct and unrelated disorders. Clin Psychol 8:463-488

Molina BSG, Marshal MP, Pelham WE, Wirth RJ (2005), Coping skills and parent support mediate the association between childhood ADHD and adolescent cigarette use. J Pediatr Psychol 30:345-357

Molina BSG, Pelham WE (2003), Childhood predictors of adolescent substance use in a longitudinal study of children with ADHD.J Abnorm Psychol 112:497-507

Molina BSG, Pelham WE, Gnagy EM, Thompson AL, Marshal, MP (2007), ADHD risk for heavy drinking and alcohol use disorder is agespecific. Alcohol Clin Exp Res 31:643-654

Muthén B, Brown CH, Booil Jo KM et al. (2002), General growth mixture modeling for randomized preventive interventions. Biostatistics 3:459-475

Muthén BO, Muthén LK (2004), Mplus User's Guide. Third Edition. Los Angeles: Muthen \& Muthen

National Household Survey on Drug Abuse (NHSDA 1992). OMB No. 0930-0110. Washington, DC: U.S. Department of Health and Human Services, Public Health Service, and Alcohol, Drug Abuse, and Mental Health Administration, National Institute on Drug Abuse.

Owens EB, Hinshaw SP, Kraemer $\mathrm{H}$ et al. (2003), Which treatment for whom for ADHD? Moderators of treatment response in the MTA. $J$ Consult Clin Psychol 71:540-552

Patterson GR, Reid JR, Dishion TJ (1992), Antisocial Boys. Eugene, OR: Castalia

Pelham WE, Fabiano G (in press), Evidence-based psychosocial treatment for attention-deficit/hyperactivity disorder. J Clin Child Adolesc Psychol

Pelham WE, Molina BSG, Gnagy EM, Meichenbaum DL, Lopez-Williams A (2005), Stimulant treatment and outcomes in the Pittsburgh ADHD
Longitudinal Study. Paper presented at 12th Scientific Meeting of International Society for Research in Child and Adolescent Psychopathology, New York, June

Schwarz G (1978), Estimating the dimension of a model. Ann Stat 6:461-464

Shaffer D, Fisher P, Lucas CP, Dulcan MK, Schwab-Stone ME (2000), NIMH diagnostic interview schedule for children version IV (NIMH DISC-IV): description, differences from previous versions, and reliability of some common diagnoses. J Am Acad Child Adolesc Psychiatry 39:28-38

Swanson JM, Kraemer HC, Hinshaw SP et al. (2001), Clinical relevance of the primary findings of the MTA: success rates based on severity of ADHD and ODD symptoms at end of treatment. J Am Acad Child Adolesc Psychiatry 40:168-179

Swanson JM, Hinshaw SP, Arnold LE, Gibbons RD, Marcus S, Hur Ket al. (2007), Secondary evaluations of MTA 36-month outcomes: propensity score and growth mixture model analyses. I Am Acad Child Adolesc Psychiatry 46:1002-1013

The MTA Cooperative Group (1999a), A 14-month randomized clinical trial of treatment strategies for attention-deficit/hyperactivity disorder. Arch Gen Psychiatry 56:1073-1086

The MTA Cooperative Group (1999b), Moderators and mediators of treatment response for children with attention-deficit/hyperactivity disorder. Arch Gen Psychiatry 56:1088-1096

The MTA Cooperative Group (2004a), National Institute of Mental Health Multimodal Treatment Study of ADHD follow-up: 24-month outcomes of treatment strategies for attention-deficit/hyperactivity disorder. Pediatrics 113:754-761

The MTA Cooperative Group (2004b), National Institute of Mental Health Multimodal Treatment Study of ADHD follow-up: changes in effectiveness and growth after the end of treatment. Pediatrics 113: 762-769

Weiss G, Hechtman LT (1993), Hyperactive Children Grown Up. ADHD in Children, Adolescents, and Adults, 2nd ed. New York: Guilford

Wells KC, Chi TC, Hinshaw SP et al. (2006), Treatment related changes in objectively measured parenting behaviors in the multimodal treatment study of children with ADHD. J Consult Clin Psychol 74: 649-657

Wells KC, Pelham WE, Kotkin RA et al. (2000), Psychosocial treatment strategies in the MTA study: rationale, methods, and critical issues in design and implementation. J Abnorm Child Psychol 28:483-505

Wilens TE, Faraone SV, Biederman J, Gunawardene S (2003), Does stimulant therapy of attention-deficit/hyperactivity disorder beget later substance abuse? A meta-analytic review of the literature. Pediatrics 111:179-185

Winters KC, Fahnhorst T (2005), Assessment issues in adolescent drug abuse treatment research. In: Recent Developments in Alcoholism, Volume 17, Alcohol Problems in Adolescents and Young Adults, Galanter M, ed. New York: Kluwer Academic/Plenum, pp 409-425

Wolfgang M, Figlio R, Tracy P, Singer S (1985), The National Survey of Crime Severity. Washington, DC: U.S. Government Printing Office 